Pacific Journal of Mathematics

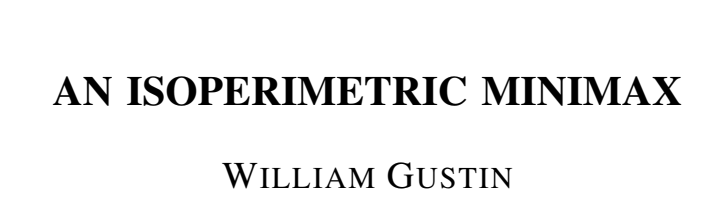




\title{
AN ISOPERIMETRIC MINIMAX
}

\author{
William Gustin
}

Introduction. In the preceding paper J. W. Green considers for a given convex body $K$ in the euclidean plane the minimum of the isoperimetric ratio $r$ (ratio of squared perimeter $l^{2}$ to area $a$ ) taken over all affine transforms $k$ of $K$. Ile then investigates the maximum value taken over all $K$ of this minimum ratio, shows by variational methods that such a maximum is attained by some polygon of five or fewer sides, and conjectures that it is, in fact, attained by a triangle with $12 \sqrt{3}$, the isoperimetric ratio of an equilateral triangle, as the minimax ratio. I shall prove this conjecture directly by refining an estimation used by Green, the precise statement of results being as follows:

I. Let $K$ be an nontriangular plane convex body; there then exists an affine transform $k$ of $K$ with $r(k)<12 \sqrt{3}$.

II. Let $T$ be a nonequilateral triangle; then $r(T)>12 \sqrt{3}$.

Before taking up the proof of these results we dispose of a lemma.

III. Let $k$ be a possibly degenerate convex body with $s \subset k \subset t$, wherein $t$ is an equilateral triangle, and $s$ a side of $t$; there then exists a number $x$ with $0 \leqq x \leqq 1$ such that

$$
\begin{aligned}
& l(k) \leqq(2 / 3+x / 3) l(t) \\
& a(k) \geqq x a(t)
\end{aligned}
$$

simultaneous equality occurring if and only if either $x=0, k=s$ or $x=1, k=t$.

Proof of III. Let $p$ be that supporting strip of $k$ parallel to the line-segment $s$; and let $x$ be the ratio of the width of $p$ to the width or altitude of $t$. Thus $0 \leqq x \leqq 1$, with $x=0$ or $x=1$ according as $k=s$ or $k=t$. Choose a point at which $k$ touches the side of $p$ opposite $s$, and define $k_{*}$ to be the triangle with this point as apex and $s$ as base. Define $k^{*}$ to be the trapezoid formed by intersection of $p$ and $t$. Clearly $s \subset k_{*} \subset k \subset k^{*} \subset t$; and $k_{*}=k=k^{*}$ if and only if $k=s$ or $k=t$.

Received October 16, 1952.

Pacific J. Math. 3 (1953), 403-405 
Since $k \supset k_{*}$, it follows that $a(k) \geqq a\left(k_{*}\right)$, with equality if and only if $k=k_{*}$. And since $k \subset k^{*}$, it follows that $l(k) \leqq l\left(k^{*}\right)$ with equality if and only if $k=k^{*}$. These inequalities become, upon the easy computation of $a\left(k_{*}\right)$ and $l\left(k^{*}\right)$, the asserted in equalities of III.

Proof of I. Let $K$ be the given nontriangular convex body. Since the area functional is continuous, it easily follows from a compactness argument that a triangle $T$ of maximal area can be inscribed in $K$. Let the three sides of $T$ be labelled $S_{i}(i=1,2,3)$, and let $V_{i}$ be that vertex of $T$ opposite $S_{i}$. Because the area of $T$ is maximal, the line $L_{i}$ through $V_{i}$ and parallel to $S_{i}$ is a line of support of $K$. The triangle formed by the three lines $L_{i}$ then circumscribes $K$ and also $T$; it is composed of four nonoverlapping congruent triangles $T$ and $T_{i}$, where $T_{i}$ is labelled so as to have $S_{i}$ as a side. That part $K_{i}$ of $K$ in $T_{i}$ is a possibly degenerate convex body with $S_{i} \subset K_{i} \subset T_{i}$. Now any triangle can be affinely transformed into any other triangle. In particular, $T$ can be affinely transformed into an equilateral triangle $t$, with $T_{i}$ going into $t_{i}, S_{i}$ into $s_{i}, K_{i}$ into $k_{i}$, and $K$ into $k$. Therefore $s_{i} \subset k_{i} \subset t_{i}$, and $t_{i}$ is congruent to $t$. According to III, ratios $x_{i}$ exist giving inequalities on $l\left(k_{i}\right)$ and $a\left(k_{i}\right)$. Furthermore, since $K$ and hence $k$ is nontriangular, not all $x_{i}=0$ and not all $x_{i}=1$. Therefore $0<x<1$, where $x=\sum x_{i} / 3$. Evidently $k$ is composed of the four nonoverlapping sets $t$ and $k_{i}$ in such a way that

$$
\begin{aligned}
& l(k)=\sum l\left(k_{i}\right)-l(t) \leqq(1+x) l(t), \\
& a(k)=\sum a\left(k_{i}\right)+a(t) \geqq(1+3 x) a(t),
\end{aligned}
$$

whereupon

$$
r(k) \leqq \frac{(1+x)^{2}}{1+3 x} r(t)=\left[1-\frac{x(1-x)}{1+3 x}\right] 12 \sqrt{3}<12 \sqrt{3},
$$

as was to be shown.

Proof of II. Through II is merely a matter of trigonometry, and very likely can be verified by exhibiting a neat but perhaps unperspicuous trigonometric identity, I shall here prove it by the sort of methods used above.

Let $T$ be a nonequilateral triangle. Define $S_{i}, V_{i}, L_{i}$ as above. Since $T$ is nonequilateral, some two of its sides, say $S_{1}$ and $S_{2}$, are unequal. Let $v_{3}$ be that point on the line $L_{3}$, regarded as a linear mirror, at which $v_{1}=V_{1}$ is reflected when viewed from $v_{2}=V_{2}$; and let $t$ be the so symmetrized isosceles triangle 
with vertices $v_{i}$ and sides $s_{i}$. Then the path $s_{1} s_{2}$ is shorter than $S_{1} S_{2}$, so $l(t)<l(T)$; and, since both triangles have the same base and altitude, $a(t)=$ $a(T)$. Therefore $r(t)<r(T)$. Consequently if the minimum isoperimetric ratio among triangles is attained, it is attained by an equilateral triangle only; whereupon it would follow that $r(T)>12 \sqrt{3}$, as was to be shown. Now all possible triangle isoperimetric ratios are realized by triangles of fixed perimeter containing a fixed point. By a compactness argument, some such triangle achieves a maximum area and hence a minimum isoperimetric ratio. This completes the proof.

INDIANA UNIVERSITY 



\section{PACIFIC JOURNAL OF MATHEMATICS}

\section{EDITORS}

\section{R. U. FOEINSON}

University of California

Berkeley 4, California

E. HewitT

University of Washington

Seattle 5 , Washington
P. P. DILWOR TH

California Institute of Technology

Pasadena 4, California

E. F. BECKENBACH

University of California

Los Angeles 24, California

\section{ASSOCIATE EDITORS}

$\begin{array}{llll}\text { H. BUSEMANN } & \text { P. R. HALMOS } & \text { BØRGE JESSEN } & \text { J. J. STOKER } \\ \text { HERBERT FFDERER } & \text { IIEINZ HOPF } & \text { PAUL LÉVY } & \text { E. G. STRAUS } \\ \text { MARSHALL, IIALI } & \text { R. D. JAMES } & \text { GEORGE PÓLYA } & \text { KÖSAKU YOSIDA }\end{array}$

\section{SPONSORS}

UNIVERSITY OF BRITISH COLUMBIA

CALIFORNIA INSTITUTE OF TECHNOLOGY.

UNIVERSITY OF CAIJIFORNIA, BERKELEY

UNIVERSITY OF CAIJIFORNIA, DAVIS

UNIVERSITY OF CALIFORNIA, LOS ANGELES

UNIVERSITY OF CALIFORNI A, SANTA BARBARA

UNIVERSITY OF NEVADA

OREGON STATE COLLEGE

UNIVERSITY OF OREGON

\author{
UNIVERSITY OF SOU TIERN CALIFORNIA \\ STANFORD RESEARCH INSTITUTE \\ STANFORD UNIVERSITY \\ WASHINGTON STATE COLLEGE \\ UNIVERSITY OF WASHINGTON \\ AMERICAN MATHEMATICAL SOCIETY \\ NATIONAL BUREAU OF STANDARDS, \\ INSTITUTE FOR NUMERICAL ANALYSIS
}

Mathematical papers intended for publication in the Pacific Journal of Mathematics should be typewritten (double spaced), and the author should keep a complete copy. Manuscripts may be sent to any of the editors except Robinson, whose term expires with the completion of the present volume; they might also be sent to M.M. Schiffer, Stanford University, Stanford, California, who is succeeding Robinson. All other communications to the editors should be addressed to the managing editor, E. F. Beckenbach, at the address given above.

Authors are entitled to receive 100 free reprints of their published papers and may obtain additional copies at cost.

The Pacific Journal of Mathematics is published quarterly, in March, June, September, and December. The price per volume (4 numbers) is $\$ 8.00$; single issues, $\$ 2.50$. Special price to individual faculty members of supporting institutions and to individual members of the American Mathematical Society: $\$ 4.00$ per volume; single issues, $\$ 1.25$.

Subscriptions, orders for back numbers, and changes of address should be sent to the publishers, University of California Press, Berkeley 4, California.

Printed at Ann Arbor, Michigan. Entered as second class matter at the Post Office, Berkeley, California.

\section{UNIVERSITY OF CALIFORNIA PRESS • BERKELEY AND LOS ANGELES}




\section{Pacific Journal of Mathematics}

\section{Vol. 3, No. 2 \\ April, 1953}

William George Bade, An operational calculus for operators with spectrum

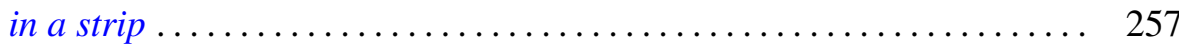

E. F. Beckenbach and Lloyd Kenneth Jackson, Subfunctions of several variables ..................................... 291

David Blackwell, Extension of a renewal theorem ................. 315

L. Carlitz, Some theorems on the Schur derivative ................ 321

Paul Arnold Clement, Generalized convexity and surfaces of negative curvature..................................... 333

Merrill M. Flood, On the Hitchcock distribution problem ............... 369

Watson Bryan Fulks, On the unique determination of solutions of the heat

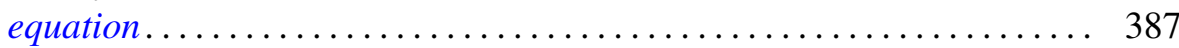

John W. Green, Length and area of a convex curve under affine transformation .................................... 393

William Gustin, An isoperimetric minimax .................. 403

Arthur Eugene Livingston, Some Hausdorff means which exhibit the Gibbs'

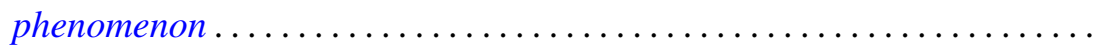

Charles Loewner, On generation of solutions of the biharmonic equation in the plane by conformal mappings ..................... 417

Gábor Szegő, Remark on the preceding paper of Charles Loewner ....... 437

Imanuel Marx and G. Piranian, Lipschitz functions of continuous

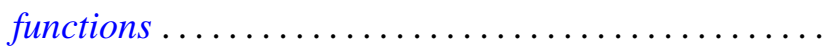

Ting-Kwan Pan, The spherical curvature of a hypersurface in Euclidean space ..

Ruth Lind Potter, On self-adjoint differential equations of second order ...

E. H. Rothe, A note on the Banach spaces of Calkin and Morrey...

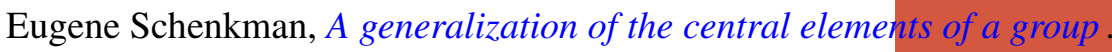

A. Seidenberg, A note on the dimension theory of rings .. . . 